\title{
Protective effect of Moringa oleifera Lam. leaf extract against carbon tetrachloride-induced neuroinflammation in a mouse model of hepatic encephalopathy
}

Samah M. Fathy ( $\nabla$ samahfathy1972@gmail.com )

Fayoum University Faculty of Science https://orcid.org/0000-0002-7870-7626

Mohammed S.M. Mohammed

Faculty of Science, Fayoum University

\section{Research}

Keywords: CCI4, Hepatic encephalopathy, Inflammation, Moringa oleifera Lam., Neuroprotection, TLR4/2MYD88/NF-KB pathway

Posted Date: April 2nd, 2021

DOl: https://doi.org/10.21203/rs.3.rs-346191/v1

License: (c) (1) This work is licensed under a Creative Commons Attribution 4.0 International License. Read Full License 


\section{Abstract \\ Background}

Hepatic encephalopathy (HE) is a neuropsychiatric disorder associated with acute or chronic liver injury. Carbon tetrachloride $\left(\mathrm{CCl}_{4}\right)$ is usually used as an experimental model for HE. The present study aimed to assess the neuroprotective impacts of Moringa oleifera Lam. leaf ethanolic extract (MOLE) against neurotoxicity in $\mathrm{CCl}_{4}$-induced mouse model of $\mathrm{HE}$.

\section{Methods}

High-performance liquid chromatography (HPLC) analysis was used for the detection of marker compounds; rutin and $\beta$-sitosterol. Animals were divided into four groups; vehicle group, $\mathrm{CCl}_{4}$ treated group, MOLE treated group, and $\left(\mathrm{CCl}_{4}+\mathrm{MOLE}\right)$ group treated with MOLE for 14 days before inducing neurotoxicity by $\mathrm{CCl}_{4}$.

\section{Results}

Pretreatment with MOLE decreased alanine aminotransferase (ALT), aspartate aminotransferase (AST), corticosterone, and ammonia levels in serum as well as it improved the antioxidant status of $\mathrm{CCl}_{4} \mathrm{treated}$ mice in the tissue of hippocampus ( $\mathrm{HC}$ ) and cerebral cortex (CC). It reduced the expression of toll-like receptor (TLR)4, TLR2, myeloid differentiation primary response 88 (MYD88), and nuclear factor kappa B (NF-KB) genes and the protein levels of the pro-inflammatory cytokines in the selected brain regions. MOLE also exhibited anti-apoptotic effect as revealed by the reduced expression of caspase3, and prevented histological deteriorations caused by $\mathrm{CCl}_{4}$ treatment. Furthermore, $\mathrm{CCl}_{4}$-induced anxiety and depression-like behavioral changes were attenuated by MOLE preadministration.

\section{Conclusions}

Taken together, the current results suggest significant anxiolytic and antidepressant effects of MOLE via modulation of neuroinflammation, oxidative stress, TLR4/2-MyD88/NF-KB pathway, and apoptosis in HE experimental model.

\section{Background}

It is well known that people with liver disease suffer from neuropsychiatric disorders due to alteration of lipid peroxidative and antioxidative mechanisms in the brain along with severe hepatic encephalopathy $(\mathrm{HE})$ propagation ${ }^{1}$. HE is a neuropsychiatric disorder propagated as a result of acute or chronic hepatic 
failure ${ }^{2}$. Carbon tetrachloride $\left(\mathrm{CCl}_{4}\right)$ is a toxic substance that is used to induce liver injury with concomitant brain disorders and can be used as an experimental model for $\mathrm{HE}^{3}$.

In the liver, $\mathrm{CCl}_{4}$ is metabolized to highly reactive free radicals which oxidize fatty acids in the phospholipids of cell membranes leading to structural and functional changes in these membranes 4 . Moreover, these free radicals along with $\mathrm{CCl}_{4}$ itself cause injuries in the endoplasmic reticulum with a consequent effect on protein synthesis and lead to lipid accumulation ${ }^{4}$. Meanwhile, $\mathrm{CCl}_{4}$ leads to the production of inflammatory mediators from the triggered macrophages in the liver with concomitant systemic inflammation exerting a critical role in aggravating neurological manifestations, possibly through triggering the brain predisposition to the associated hyperammonemia ${ }^{5}$.

Neuroinflammation and oxidative stress have been evidenced to be involved in the development of depression and anxiety ${ }^{6}$. Noteworthy, $\mathrm{CCl}_{4}$ has been reported to induce neuropsychiatric disorders mimicking what appear in patients with acute or chronic liver damage via targeting brain antioxidative system and inflammatory pathways such as toll-like receptor (TLR)4/nuclear factor kappa B (NF-kB) pathway ${ }^{1}$. Moreover, it has been reported that corticotrophin-releasing factor (CRF) hypersecretion in response to the release of pro-inflammatory cytokines is attributable to the modification of hypothalamicpituitary-adrenal (HPA)-axis resulting in an elevated level of plasma corticosterone and depression symptoms' exacerbation ${ }^{7}$.

Plants are well known for having therapeutic effects and have been used in this regard in traditional and modern medications. Moringa oleifera Lam. (MOL), family Moringaceae ${ }^{8}$ is widely known as "Miracle tree" as a result of its medicinal outcomes. Leaves, the most common and suitable part of the plant for medicinal commercial mass production ${ }^{9}$ can be consumed in different ways and can also be dried and stored for months without losing nutritional benefits ${ }^{10}$. The following compounds were recorded in our previous study in Moringa oleifera Lam. leaf ethanolic extract (MOLE); quercetagetin-7-0-glucoside, quercetin 3,5,7,3',4'-pentamethyl ether, and $\beta$-sitosterol along with other phytochemicals using gas chromatography-mass spectrometry (GC-MS) analysis ${ }^{11}$. Moreover, the total phenolic and the total flavonoid contents in MOLE were also measured ${ }^{11}$. Furthermore, it has been reported that MOL possesses pain relief, anti-depression, anti-inflammatory, immunomodulatory, and neuroprotective activities ${ }^{12}$.

The current study is the first-ever to evaluate the possible role of MOLE as a protective adjuvant against brain manifestations induced by $\mathrm{CCl}_{4}$ in $\mathrm{HE}$ mouse model. The alleviation potentials of MOLE were assessed by tracking its effect on TLR4/2-MyD88/NF-KB pathway, neuroinflammation, apoptosis, oxidative stress, anxiety and depression-like behavior, and histopathological changes in the hippocampus $(\mathrm{HC})$ and cerebral cortex $(\mathrm{CC})$ regions of the mouse brain.

\section{Methods}




\section{Chemicals}

$\mathrm{CCl}_{4}$ was purchased from Sigma (St. Louis, MO, USA). All other chemicals and reagents used were of the highest analytical grade.

\section{MOL source and identification}

The source for the plant leaves was from Jazan city, KSA with latitude $16^{\circ} 53^{\prime} 12.59^{\prime \prime} \mathrm{N}$ and longitude: $42^{\circ} 33^{\prime} 23.99^{\prime \prime}$ E coordinates according to degrees minutes seconds (DMS). The authentication of the plant was carried out by taking the herbarium specimens found at Jazan University Herbarium (JAZUH), $\mathrm{KSA}$, as a reference.

\section{Preparation of MOLE}

MOL leaves were washed, dried, and finally ground. $96 \%$ ethanol was mixed with the ground leaves and the mixture was kept in the shaking incubator for $24 \mathrm{~h}$ at $37^{\circ} \mathrm{C}$. The obtained extract was then filtered and put in the rotary evaporator at $40^{\circ} \mathrm{C}$ until complete evaporation of ethanol. Finally, a semi-solid extract was produced and stored at $4{ }^{\circ} \mathrm{C}$ until use.

\section{High-performance liquid chromatography (HPLC) analysis}

MOLE was analyzed using HPLC method for a qualitative analysis of two marker compounds. About 50 $\mathrm{mg}$ of the extract were dissolved in $25 \mathrm{~mL}$ methanol and injected into an HPLC (Agilent 1200 series, UV detector). For rutin, Agilent Eclipse XDB-C18 $(150 \times 4.6 \mathrm{~mm}, 5 \mu \mathrm{m})$, wavelength $254 \mathrm{~nm}$, and flow rate of 1 $\mathrm{mL} / \mathrm{min}$. The mobile phase consisted of acetonitrile: water $/ 0.1$ formic acid with gradient increased from $5 \%$ to $95 \%$ over $15 \mathrm{~min}$. For $\beta$-sitosterol, a waters symmetry shield C18 column $(150 \times 4.6,5 \mu \mathrm{m})$ and wavelength $210 \mathrm{~nm}$ was used. The mobile phase consisted of methanol: acetonitrile with the ratio 30:70 $(\mathrm{v} / \mathrm{v})$, with a flow rate of $1.0 \mathrm{~mL} / \mathrm{min}$.

\section{Experimental design}

Adult healthy BALB/c male albino mice weighting $20-25 \mathrm{~g}$ (8 weeks old) were brought from the National Cancer Institute ( $\mathrm{NCl})$. Throughout the experiment, animals were kept in conventional cages at the standard conditions of temperature, humidity, and light/dark cycle. Animals had free access to the standard food and drink ad libitum. Animal experimentation protocols were carried out following the National Institutes of Health $(\mathrm{NIH})$ guidelines for animal experimentation and approved by Cairo University Institutional Animal Care and Use Committee (CU-IACUC), Egypt, (permission number: CU/I/F/41/20).

The experiment lasted for 15 days following 1-week acclimatization. Animals were haphazardly divided into 4 groups with 8 mice in each group; Control group (group 1), $\mathrm{CCl}_{4}$-treated group (group 2), MOLEtreated group (group 3), and $\mathrm{CCl}_{4}+\mathrm{MOLE}-$ treated group (group 4). The first two groups received distilled water orally by gavage on daily basis for consecutive 14 days. The last two groups received MOLE (400 
$\mathrm{mg} / \mathrm{kg}$ body weight) ${ }^{13}$ orally by gavage daily for consecutive 14 days. Then on day 15 , group 2 and group 4 were administered a single dose of $\mathrm{CCl}_{4}(1 \mathrm{~mL} / \mathrm{kg}$ body weight) prepared by dilution in olive oil; 1:1 (v/v), intraperitoneally (i.p.) ${ }^{1,14}$, while other groups (groups 1 \& 3) received olive oil, (i.p). 24 hours later, behavioral tests were carried out in separate animal groups ${ }^{1}$. Euthanasia was conducted by decapitation under xylazine/ketamine anesthesia ${ }^{15}$.

\section{Estimation of depression-like behavior by forced swimming test (FST) and tail suspension test (TST)}

FST was carried out as described by Porsolt et al. (1977) ${ }^{16}$. Initially, each mouse was placed into water at a depth of $20 \mathrm{~cm}$ and a temperature of $23 \pm 2{ }^{\circ} \mathrm{C}$ inside a transparent cylinder. Afterward, the mice individually were forced to swim for $6 \mathrm{~min}$. The time of immobility was recorded by considering the halt of escape-oriented behavior during the last $5 \mathrm{~min}$.

TST was also executed as reported by Steru et al. (1985) ${ }^{17}$. For $6 \mathrm{~min}$, each mouse was hung about $1 \mathrm{~cm}$ from the tip of the tail by using sticky tape on the edge of a rod at a height of $50 \mathrm{~cm}$ above the floor. The duration of immobility time was considered by recording the time during which each mouse was suspended without any activity or any motion in the last $5 \mathrm{~min}$.

\section{Collection of blood and tissue samples}

The blood was collected and the serum was isolated by centrifugation of the blood at $2000 \mathrm{xg}$ for $15 \mathrm{~min}$ at $4{ }^{\circ} \mathrm{C}$ for biochemical analysis.

Brains were dissected from the skull. For the histopathological investigation, one side of each brain was kept in $10 \%$ neutral buffered formalin for later use. HC and CC were excised from the other side and assigned into two portions. The first portion of each region was homogenized, centrifuged at $5000 \mathrm{xg}$, and the protein concentration was evaluated in the tissue supernatant according to the Bradford method by using Biorad assay kit ${ }^{18}$. The analysis of oxidative stress parameters and pro-inflammatory cytokines in the supernatant was followed. The second portion from each brain region was collected in RNA lysis buffer for measuring gene expression of the inflammatory and apoptotic mediators. For the histopathological investigation, brains were kept in $10 \%$ neutral buffered formalin.

\section{Histopathological examination}

After washing the tissue samples, a series of diluted alcohol was used for dehydration, followed by clearance in xylene, infiltration in paraffin wax, and embedding in paraffin wax blocks. For the histopathological investigation, $5 \mu \mathrm{m}$ thickness coronal sections were obtained and stained with Ehrlich's hematoxylin and eosin (H\&E) as demonstrated by Bancroft and Gamble (2008) ${ }^{19}$. The thickness of dentate gyrus (DG) in $\mathrm{HC}$ was measured in different groups using ImageJ software.

\section{Quantitative reverse transcription-polymerase chain reaction (RT-qPCR) assay}


Total RNA was isolated from the HC and CC tissues using SV Total RNA Isolation System (Promega Corporation, Madison, WI, USA) as previously described ${ }^{20}$. RNA concentration and purity were analyzed using NanoDrop ${ }^{\text {TM }}$ 2000/2000c Spectrophotometer (ThermoScientific, Lo, UK). Complementary DNA (cDNA) was then produced using SuperScript III First-Strand Synthesis System according to the manufacturer's instructions (Fermentas, Waltham, MA, USA). The cDNA yield was then used to detect the relative expression levels of TLR2, TLR4, myeloid differentiation primary response 88 (MYD88), and NFKB genes. Glyceraldehyde 3-phosphate dehydrogenase (GAPDH) housekeeping gene was used for data normalization. Table 1 shows the primers' sequences of mice's genes that have been used in the present study.

\section{Determination of proinflammatory cytokines in $\mathrm{HC}$ and $\mathrm{CC}$}

The protein level of tumor necrosis factor (TNF)- $a$ and interleukin (IL)- 6 was detected in HC and CC supernatant by enzyme-linked immunosorbent assay (ELISA) kits particularly for mice (Merck Millipore, San Francisco, California, USA) following the producer's protocol. Protein levels were measured using the microplate ELISA reader at $450 \mathrm{~nm}$.

\section{Evaluation of biochemical parameters}

Alanine aminotransferase (ALT) and aspartate aminotransferase (AST) levels in serum

Liver functions were checked by measuring ALT as described by Hafkenscheid and Dijt (1979) ${ }^{21}$ and AST according to Sampson et al. (1980) ${ }^{22}$ in serum using the enzymatic methods.

Detection of ammonia level in serum

Ammonia assay was used to assess the level of ammonia in serum, as described by Gutiérrez-de-Juan et al. (2017) ${ }^{23}$. The reaction of Nessler's reagent is the key to detect ammonia production using ammonium chloride as a standard. The spectrophotometer was used at $425 \mathrm{~nm}$ and the results were presented in percentage.

\section{Evaluation of corticosterone level in serum}

Serum corticosterone concentration was determined in serum by using ELISA kits (ThermoScientific, Lo, UK) as per the manufacturer's instructions.

\section{Determination of malondialdehyde (MDA) level in the HC and CC}

Measurement of lipid peroxidation (LPO) in the homogenates' supernatant of each brain region was carried out based on thiobarbituric acid (TBA) reaction with MDA ${ }^{24}$. The principle for the reaction is the formation of a product due to LPO of the membranes. After incubation, the spectrophotometer was used to record the absorbance at $532 \mathrm{~nm}$ (MDA Colorimetric/Fluorometric Assay kit, Biovision Inc., CA, USA). 
OxiSelect Superoxide dismutase (SOD) kit (CellBiolabs, Inc., CA, USA) was used for the detection of the activity of SOD as described by the producer's protocol following the method reported by (Valentine and Hart, 2003) ${ }^{25}$. The absorbance was recorded spectrophotometrically at $540 \mathrm{~nm}$.

Reduced glutathione (GSH) level was measured using the method modified by Jollow et al. (1974) ${ }^{26}$. The basis for the assay depends on the formation of yellow color as a result of the reaction between 5, 5dithiobis-2 nitro benzoic acid (DTNB) and free thiol groups of GSH. The absorbance was assessed spectrophotometrically at $412 \mathrm{~nm}$.

\section{Statistical methods}

Statistical analyses were performed using GraphPad PRISM (version 8.4.3 (686); Graph Pad Software, USA). Data were represented as mean $\pm S D$. analyses were done using one-way analysis of variance (ANOVA) followed by Tukey's multiple comparison test. Differences were considered significant at $\mathrm{P}<$ 0.05 .

\section{Results}

\section{Rutin and $\beta$-sitosterol detection by HPLC}

For HPLC analysis, the authentic reference standards of rutin and $\beta$-sitosterol were analyzed using an identical chromatographic method. By comparing peaks' retention times, rutin and $\beta$-sitosterol were identified in MOLE (Fig. 1).

\section{MOLE pretreatment reverses the increase in serum aminotransferases, ammonia, and corticosterone levels induced by $\mathrm{CCl}_{4}$}

$\mathrm{CCl}_{4}$ treatment for 24 hours remarkably increased ALT $(\mathrm{P}<0.01)$ and AST $(\mathrm{P}<0.001)$. These increases were markedly prevented in response to MOLE pretreatment at significances of $(P<0.01)$ and $(P<0.001)$ for ALT and AST, respectively (Fig. $2 \mathrm{~A}, \mathrm{~B}$ ).

An obvious elevation in serum ammonia level was manifested in $\mathrm{CCl}_{4}$-treated mice $(\mathrm{P}<0.0001)$. However, MOLE pretreatment remarkably reversed this change $(P<0.0001)$, Fig. $2(C)$.

Serum corticosterone level was measured to investigate the potential role of MOLE against the alteration in HPA-axis induced by $\mathrm{CCl}_{4}$ treatment. A significant increase in serum corticosterone level was found in $\mathrm{CCl}_{4}$-treated mice $(\mathrm{P}<0.01)$. However, this increase was markedly prevented upon MOLE pretreatment $(\mathrm{P}$ < 0.01), Fig. 2 (D).

MOLE pretreatment alleviates oxidative stress induced by $\mathrm{CCl}_{4}$ 
The role of MOLE pretreatment against $\mathrm{CCl}_{4} \mathrm{LPO}$ was investigated by measuring MDA in the $\mathrm{HC}$ and CC brain tissues. $\mathrm{CCl}_{4}$ markedly elevated $\mathrm{LPO}$ in both $\mathrm{HC}$ and $\mathrm{CC}$ as evidenced by the striking increase in MDA $(P<0.0001)$. This effect was remarkably attenuated in both tissues in the presence of MOLE pretreatment $(P<0.001)$, Fig. $3(A, B)$.

To evaluate the potential antioxidant power of MOLE against $\mathrm{CCl}_{4}$ neurotoxicity, SOD and GSH levels were measured in the $\mathrm{HC}$ and $\mathrm{CC}$ brain tissues. $\mathrm{CCl}_{4}$ markedly enhanced the oxidative stress as evidenced by the significant decrease in SOD and GSH levels in the HC $(P<0.05)$ and $C C(P<0.01)$. However, MOLE administration before $\mathrm{CCl}_{4}$ treatment significantly attenuated these decreases in both tissues $(\mathrm{P}<0.05)$, Fig. 3 (C-F).

\section{The effect of MOLE pretreatment against inflammatory response initiated by $\mathrm{CCl}_{4}$}

MOLE pretreatment effect on TLR4/2-MyD88/NF-KB pathway

To evaluate the role of MOLE pretreatment on the TLR4/2-MyD88/NF-kB pathway, RT-qPCR was used to measure the expression of TLR2, TLR4, MyD88, and NF-KB genes in the $\mathrm{HC}$ and CC brain tissues. $\mathrm{CCl}_{4}$ markedly raised the gene expression of TLR2 $(P<0.001)$, TLR4 $(P<0.001)$ and MyD88 $(P<0.0001)$ in both brain regions. NF-KB gene expression also upregulated significantly in response to $\mathrm{CCl}_{4}$ toxicity in the HC $(P<0.01)$ and $C C(P<0.05)$. Most of these increases were significantly alleviated in response to MOLE pretreatment. TLR2 gene expression was significantly decreased in both $\mathrm{HC}(\mathrm{P}<0.01)$ and $\mathrm{CC}(\mathrm{P}<$ 0.001). TLR4 was significantly decreased in both tissues as well $(P<0.001)$. Marked restoration of MyD88 gene expression was also noticed $(P<0.0001)$. Although a decrease in NF-KB gene expression was noticed in both tissues, it was only significant in the HC $(P<0.01)$, (Table 2$)$.

MOLE pretreatment reverses alterations in TNF-a and IL-6 levels induced by $\mathrm{CCl}_{4}$

The effect of MOLE pretreatment on the inflammatory mediators activated by $\mathrm{CCl}_{4}$ was evaluated by measuring TNF- $a$ and IL-6 protein levels in the $\mathrm{HC}$ and $\mathrm{CC}$ brain tissues in different groups. $\mathrm{CCl}_{4}$ significantly elevated the protein levels of TNF- $a$ and IL- 6 in both HC and CC $(P<0.01)$. Nevertheless, pretreatment with MOLE remarkably prevented these elevations in the $\mathrm{HC}(P<0.05)$ and $C C(P<0.01)$, (Table 2).

\section{MOLE exhibits an antiapoptotic effect against $\mathrm{CCl}_{4}$ neurotoxicity}

Caspase 3 gene expression was measured in the $\mathrm{HC}$ and $\mathrm{CC}$ brain tissues to assess the antiapoptotic effect of MOLE against $\mathrm{CCl}_{4}$ neurotoxicity. A remarkable increase in caspase 3 gene expression was manifested in both brain tissues in response to $\mathrm{CCl}_{4}$ toxicity $(P<0.0001)$. However, MOLE was found to have an antiapoptotic role against this effect as evidenced by the striking decrease in caspase 3 gene expression in both tissues $(P<0.0001)$, (Table 2$)$. 
FST and TST were performed to investigate the protective role of MOLE pretreatment against depressionlike behaviors manifested by $\mathrm{CCl}_{4}$-treated mice. Depression-like behaviors represented by mice immobility in seconds after FST and TST were recorded. It was found that $\mathrm{CCl}_{4}$ markedly increased depression-like behaviors based on both FST $(P<0.01)$ and TST $(P<0.0001)$. Nevertheless, pretreatment with MOLE had a marked anxiolytic effect as evidenced by FST $(P<0.01)$ and TST $(P<0.001)$, (Fig. 4).

\section{MOLE pretreatment protects against histopathological changes induced in brain regions by $\mathrm{CCl}_{4}$}

Coronal sections in the $\mathrm{HC}$ and $\mathrm{CC}$ were stained with $\mathrm{H} \& \mathrm{E}$ to assess the neuroprotective effect of MOLE against histopathological alterations induced by $\mathrm{CCl}_{4}$. $\mathrm{CCl}_{4}$ induced histopathological changes including thinning of the DG region in the HC (Fig. 5) and neuron degeneration (Nd) in the CC (Fig. 6). However, MOLE pretreatment alleviates these changes significantly.

\section{Discussion}

$\mathrm{HE}$ is ascribed with hyperammonemia in the bloodstream that can pass via the blood-brain barrier (BBB) and causes damage to the brain tissue ${ }^{3}$. The mechanism for brain injury associated with HE was reported to be through oxidative stress, inflammatory response, and dysfunction of energy metabolism ${ }^{3}$. It was previously documented that $\mathrm{CCl}_{4}$ treatment can successfully stimulate liver injury along with $\mathrm{HE}$ associated brain tissue damage ${ }^{3}$. For confirmation, the current experiment revealed that serum levels of liver enzymes; ALT and AST, elevated significantly in $\mathrm{CCl}_{4}$-induced mice when compared with the control group. Pretreatment with MOLE halts the increase of ALT and AST levels in $\mathrm{CCl}_{4}$-treated mice.

In the present study, $\mathrm{CCl}_{4}$ induced oxidative stress whereas MOLE pretreatment protected brain tissue from oxidative stress damage. An increase of MDA and a decrease of the level of antioxidants were observed in $\mathrm{HC}$ and $\mathrm{CC}$ following $\mathrm{CCl}_{4}$ injection in the current study. Hepatocyte damage is initiated by CYP450- mediated bioactivation of $\mathrm{CCl}_{4}$ into reactive free radicals; trichloromethyl $\left(\mathrm{CCl}_{3}\right)$ and trichloromethyl peroxy radical $\left(\mathrm{CCl}_{3} \mathrm{OO}\right)$. This activates the release of reactive oxygen species (ROS) which leads to LPO ${ }^{27}$. The severity of LPO of cell membranes can be monitored via assessing the formed MDA in brain tissue ${ }^{28}$. Moreover, the decline of GSH and SOD levels was reportedly due to ROS release in the $\mathrm{CCl}_{4}$ mouse model of encephalopathy ${ }^{29}$. The dysregulated antioxidant mechanism in the current model was in line with previous reports ${ }^{1,30}$, in which an elevated MDA and reduced antioxidant mechanism in different brain regions were observed following $\mathrm{CCl}_{4}$ intoxication. MOLE pretreatment successfully restored the antioxidative power in $\mathrm{HC}$ and $\mathrm{CC}$ through the reduction of MDA and restoration of antioxidative mechanisms which was in agreement with Idoga et al., (2018) ${ }^{31}$. The reversed alterations of antioxidant power in $\mathrm{MOLE} / \mathrm{CCl}_{4}$ treated mice indicate the neuroprotective effect of MOLE and its prominent antioxidant capacity protecting against LPO.

It was recorded that Inflammation is a crucial inducer for HE ${ }^{32}$. Liver damage was associated with peripheral inflammation with cytokine storming that can cross BBB with ascribed neuroinflammation 
disorders ${ }^{32}$. To evaluate the protective effects of MOLE against neuroinflammation consequences in $\mathrm{HC}$ and $\mathrm{CC}$ regions of $\mathrm{CCl}_{4}$ injected mice, relative expressions of TLR2, TLR4, MyD88, and NF-KB genes as well as the protein levels of TNF- $a$ and IL- 6 were measured.

Toll-like receptors (TLRs) play major roles in inflammatory responses ${ }^{33}$. TLR2 and TLR4 are considered as neuroinflammatory receptors that are residential in neurons, astrocytes, and microglia ${ }^{34}$. The adaptor protein of almost all TLRs is MyD88 and acts as a link between the receptors and the downstream signaling components with subsequent activation of transcription and inflammatory responses ${ }^{34}$. In the current experiment, up-regulation of TLR4, TLR2, and MyD88 gene expressions were detected in $\mathrm{CCl}_{4}$ treated mice. Our findings were consistent with previous studies ${ }^{32,35}$, in which upregulated TLR4, TLR2, and MyD88 gene expressions were noticed in HE rat model. MOLE interferes with this cascade as evidenced by the downregulation of TLR4, TLR2, and MyD88 gene expressions manifested by $\mathrm{CCl}_{4} / \mathrm{MOLE}$ treated group.

Gene expression of NF-KB was also elevated in the present $\mathrm{CCl}_{4}$ treated mice, which was downregulated by MOLE pretreatment. It has been reported that activating TLR4/2-MyD88 dependent signaling pathway leads to NF-KB transcription ${ }^{35}$. Consequently, TLR4/2-MyD88/NF-KB signaling pathway might be targeted by MOLE in the mitigation of $\mathrm{CCl}_{4}$ toxicity.

TLR4, a member of TLRs, has been evidenced to play a significant role in initiating the inflammatory response after brain damage ${ }^{36}$. In the present study, we found an increase in proinflammatory cytokines in the $\mathrm{CCl}_{4}$ group which was prevented in $\mathrm{CCL}_{4}+\mathrm{MOLE}$ group. $\mathrm{CCl}_{4}$ toxicity increases the levels of proinflammatory cytokines produced by Kupffer cells. Consequently, liver stromal cells are recruited to assist in intensifying the inflammatory response via the production of cytokines and chemokines ${ }^{37}$. This peripheral intensification in inflammatory response promotes the activation of microglia and TLR4. Microglial activation is ascribed with the secretion of pro-inflammatory cytokines such as IL-6 and TNF-a that were associated with the brain deteriorations observed in $\mathrm{CCl}_{4}$ treated mice ${ }^{38}$. Whereas, activation of TLR4 exacerbates the inflammatory reactions by inducing NF-KB pathway leading to the generation of proinflammatory factors ${ }^{39}$.

It has been established that oxidative stress and neuroinflammation are associated with neurobehavioral changes ${ }^{40}$. For instance, proinflammatory cytokines such as IL-1 $\beta, \mathrm{IL}-6$, and TNF- $a$ have been demonstrated to be elevated in depression and anxiety, implying immune dysregulation ${ }^{41}$. Moreover, symptoms of depression were proven to be aggravated by pro-inflammatory cytokines which lead to disturbance of HPA-axis as a result of hypersecretion of CRF with elevated corticosterone level in plasma and subsequent induction of depression symptoms ${ }^{1,7}$. Subsequently, the neuroprotective effect of MOLE against $\mathrm{CCl}_{4}$-induced anxiety and depression-like behavioral changes via FST and TST was assessed. $\mathrm{CCl}_{4}$-induced anxiety and depression-like behavioral changes observed in the current study agree with a previous report ${ }^{1}$. However, pretreatment with MOLE significantly improved the behavioral status of mice. 
This may indicate that MOLE contains anxiolytic and anti-depression phytochemicals. These phytochemicals could be acting on serotonergic, dopaminergic, and/or noradrenergic neurotransmitter systems ${ }^{42}$.

Besides, the elevated level of corticosterone in $\mathrm{CCl}_{4}$-treated mice was alleviated by MOLE pretreatment in the current study confirming the previously reported antidepressant effect of MOLE ${ }^{12}$.

An increased level of ammonia in serum was observed in $\mathrm{CCl}_{4}$ group in agreement with previous findings 1. Ammonia exists in biological solutions in two forms; $\mathrm{NH}_{3}$ and $\mathrm{NH}_{4}{ }^{+}$. $\mathrm{CCl}_{4}$-induced liver damage results in hyperammonemia represented by increased levels of circulating ammonia ${ }^{43}$. Hyperammonemia has been implicated in neurological disorders through activating brain oxidative stress and neuroinflammation ${ }^{44}$. Hyperammonemia results from liver injury and ammonia can easily pass through BBB causing neurotoxicity 45 .

In the current study, the antiapoptotic effect of MOLE pretreatment against $\mathrm{CCl}_{4}$-induced apoptosis was evaluated by assessing relative caspase 3 mRNA level. A decrease in caspase 3 expression in the presence of MOLE confirms the antidepressant effect of MOLE as suggested by Khan et al. (2019) 46 . Apoptosis can be triggered via inflammatory response or ROS generated by $\mathrm{CCl}_{4}{ }^{47}$. It can also be explained by the pro-apoptotic effect of corticosteroids on the brain regions especially $\mathrm{HC}^{48}$. Consequently, neuroinflammation, oxidative stress, along with apoptosis in the brain cells, can cause anxiety and depression-like behaviors ${ }^{46}$. However, our results proved the anxiolytic and anti-depression properties of MOLE.

To further explore the mechanisms behind the neuroprotective effect of MOLE against $\mathrm{CCl}_{4}$-induced neurotoxicity, histopathology of $\mathrm{CC}$ and $\mathrm{HC}$ was assessed using H\&E. The thickness of the DG cellular layer in $\mathrm{HC}$ region in $\mathrm{CCl}_{4}$-challenged mice was found to be markedly thinner than that of the control mice. This agrees with a previous study ${ }^{46}$. $\mathrm{Nd}$ was also manifested in the $\mathrm{CC}$ of $\mathrm{CCl}_{4}$-treated mice in agreement with Shaalan et al. (2017) ${ }^{49}$. However, MOLE evidently attenuated these alterations. Histopathological results were consistent with the biochemical findings.

\section{Conclusions}

The present study demonstrates, for the first time, the neuroprotective role of MOLE against $\mathrm{CCl}_{4}$-induced neurotoxicity through biochemical, molecular, behavioral, and histological examinations. MOLE attenuated neuroinflammation, brain oxidative stress, apoptosis, biochemical alterations, and histopathological changes in $\mathrm{HC}$ and CC. Furthermore, MOLE significantly improved anxiety and depression-like behaviors. Accordingly, MOLE may be used in the prevention of HE related brain dysfunctions.

\section{Declarations}




\section{Ethics approval and consent to participate}

Ethical approval was received from Cairo University Institutional Animal Care and Use Committee (CUIACUC), Egypt, (permission number: CU/I/F/41/20). For consent to participate, it is not applicable.

\section{Consent for publication}

Not applicable.

\section{Availability of data and materials}

The authors declare that the datasets used and/or analysed during the current study are available from the corresponding author on reasonable request.

\section{Competing interests}

The authors declare that they have no competing interests.

\section{Funding}

This research received no specific grant from any funding agency in the public, commercial or notfor-profit sectors.

\section{Authors' contributions}

SMF and MSMM suggested the research point of the study, designed the experimental protocol, involved in the implementation of the overall study, performed the statistical analyses of the study, researched the data, and wrote the manuscript. Both authors contributed to the critical revision of the manuscript.

\section{Acknowledgments}

We are grateful to Prof. Layla Rashed (Faculty of Medicine, Cairo University, Egypt) for her technical support.

\section{Abbreviations}

ALT: alanine aminotransferase; ANOVA: one-way analysis of variance; AST: aspartate aminotransferase; BBB: blood-brain barrier; $\mathrm{CCl}_{3}$ : trichloromethyl; $\mathrm{CCl}_{3} \mathrm{OO}$ : trichloromethyl peroxy radical; $\mathrm{CCl}_{4}$ : carbon tetrachloride; CC: cerebral cortex; CDNA: complementary DNA; CRF: corticotrophin-releasing factor; CUIACUC: Cairo University Institutional Animal Care and Use Committee; DG: dentate gyrus; DMS: degrees minutes seconds; DTNB: 5, 5-dithiobis-2 nitro benzoic acid; ELISA: enzyme-linked immunosorbent assay; FST: forced swimming test; GAPDH: Glyceraldehyde 3-phosphate dehydrogenase; GSH: reduced glutathione; HE: hepatic encephalopathy; HC: hippocampus; H\&E: hematoxylin and eosin; HPLC: Highperformance liquid chromatography; HPA: hypothalamic-pituitary-adrenal; IL: interleukin; i.p.: 
intraperitoneally; JAZUH: Jazan University Herbarium; LPO: lipid peroxidation; MDA: malondialdehyde; MOLE: Moringa oleifera Lam. leaf ethanolic extract; MYD88: myeloid differentiation primary response 88; $\mathrm{NCl}$ : National Cancer Institute; Nd: neuron degeneration; NF-kB: nuclear factor kappa B; NIH: National Institutes of Health; ROS: reactive oxygen species; RT-qPCR: quantitative reverse transcription-polymerase chain reaction; SOD: superoxide dismutase; TBA: thiobarbituric acid; TLR: toll-like receptor; TNF: tumor necrosis factor; TST: tail suspension test.

\section{References}

1. Shal B, Khan A, Naveed M, et al. Neuroprotective effect of 25-Methoxyhispidol A against CCl4induced behavioral alterations by targeting VEGF/BDNF and caspase-3 in mice. Life Sci. Published online 2020:117684.

2. El-Marasy SA, El Awdan SA, Abd-Elsalam RM. Protective role of chrysin on thioacetamide-induced hepatic encephalopathy in rats. Chem Biol Interact. 2019;299:111-19.

3. de Souza Machado F, Marinho JP, Abujamra AL, Dani C, Quincozes-Santos A, Funchal C. Carbon tetrachloride increases the pro-inflammatory cytokines levels in different brain areas of Wistar rats: the protective effect of acai frozen pulp. Neurochem Res. 2015;40(9):1976-83.

4. Yue S, Xue N, Li H, Huang B, Chen Z, Wang X. Hepatoprotective Effect of Apigenin Against Liver Injury via the Non-canonical NF-кB Pathway In Vivo and In Vitro. Inflammation. Published online 2020.

5. Aldridge DR, Tranah EJ, Shawcross DL. Pathogenesis of hepatic encephalopathy: role of ammonia and systemic inflammation. J Clin Exp Hepatol. 2015;5:S7-S20.

6. Mello BSF, Monte AS, McIntyre RS, et al. Effects of doxycycline on depressive-like behavior in mice after lipopolysaccharide (LPS) administration. J Psychiatr Res. 2013;47(10):1521-29.

7. Furtado M, Katzman MA. Examining the role of neuroinflammation in major depression. Psychiatry Res. 2015;229(1-2):27-36.

8. Fakurazi S, Sharifudin SA, Arulselvan P. Moringa oleifera hydroethanolic extracts effectively alleviate acetaminophen-induced hepatotoxicity in experimental rats through their antioxidant nature. Molecules. 2012;17(7):8334-50.

9. Mahdi HJ, Khan NAK, Asmawi MZ Bin, Mahmud R, Vikneswaran A, Murugaiyah L. In vivo antiarthritic and anti-nociceptive effects of ethanol extract of Moringa oleifera leaves on complete Freund's adjuvant (CFA)-induced arthritis in rats. Integr Med Res. 2018;7(1):85-94.

10. Tesfay SZ, Bertling I, Odindo AO, Workneh TS, Mathaba N. Levels of anti-oxidants in different parts of moringa (Moringa oleifera) seedling. African J Agric Res. 2011;6(22):5123-32.

11. Fathy SM, Mohammed MSM. Moringa oleifera Lam. leaf extract mitigates carbon tetrachloridemediated hepatic inflammation and apoptosis via targeting oxidative stress and toll-like receptor 4/ nuclear factor kappa B pathway in mice. Food Sci Hum wellness. 2021;10:382-90.

12. Kou X, Li B, Olayanju JB, Drake JM, Chen N. Nutraceutical or pharmacological potential of Moringa oleifera Lam. Nutrients. 2018;10(3):343. 
13. Singh D, Arya PV, Aggarwal VP, Gupta RS. Evaluation of antioxidant and hepatoprotective activities of Moringa oleifera Lam. leaves in carbon tetrachloride-intoxicated rats. Antioxidants. 2014;3(3):569-91.

14. Makni $M$, Chtourou $Y$, Barkallah $M$, Fetoui $H$. Protective effect of vanillin against carbon tetrachloride (CCl4)-induced oxidative brain injury in rats. Toxicol Ind Health. 2012;28(7):655-62.

15. Nunes-Souza V, Alenina N, Qadri F, et al. CD36/sirtuin 1 axis impairment contributes to hepatic steatosis in ACE2-deficient mice. Oxid Med Cell Longev. 2016;2016.

16. Porsolt RD, Bertin A, Jalfre M. Behavioral despair in mice: a primary screening test for antidepressants. Arch Int Pharmacodyn Ther. 1977;229(2):327.

17. Steru L, Chermat R, Thierry B, Simon P. The tail suspension test: a new method for screening antidepressants in mice. Psychopharmacology (Berl). 1985;85(3):367-70.

18. Bradford MM. A rapid and sensitive method for the quantitation of microgram quantities of protein utilizing the principle of protein-dye binding. Anal Biochem. 1976;72(1-2):248-54.

19. Bancroft JD, Gamble M. Theory and Practice of Histological Techniques. Elsevier health sciences; 2008.

20. Fathy S, Said N. Immunomodulation and antigenotoxic effects of propolis in paclitaxel-treated rats. Egypt J Zool. 2019;72(72):45-56.

21. Hafkenscheid JC, Dijt CC. Determination of serum aminotransferases: activation by pyridoxal-5'phosphate in relation to substrate concentration. Clin Chem. 1979;25(1):55-59.

22. Sampson EJ, Whitner VS, Burtis CA, McKneally SS, Fast DM, Bayse DD. An interlaboratory evaluation of the IFCC method for aspartate aminotransferase with use of purified enzyme materials. Clin Chem. 1980;26(8):1156-64.

23. Gutiérrez-de-Juan V, López de Davalillo S, Fernández-Ramos D, et al. A morphological method for ammonia detection in liver. PLoS One. 2017;12(3):e0173914.

24. Ohkawa $\mathrm{H}$, Ohishi N, Yagi K. Assay for lipid peroxides in animal tissues by thiobarbituric acid reaction. Anal Biochem. 1979;95(2):351-58.

25. Valentine JS, Hart PJ. Misfolded CuZnSOD and amyotrophic lateral sclerosis. Proc Natl Acad Sci. 2003;100(7):3617-22.

26. Jollow DJ, Mitchell JR, Zampaglione N al, Gillette JR. Bromobenzene-induced liver necrosis. Protective role of glutathione and evidence for 3, 4-bromobenzene oxide as the hepatotoxic metabolite. Pharmacology. 1974;11(3):151-69.

27. Risal P, Hwang PH, Yun BS, et al. Hispidin analogue davallialactone attenuates carbon tetrachlorideinduced hepatotoxicity in mice. J Nat Prod. 2012;75(10):1683-89.

28. LIu Z, TIan J. Changes of MDA and SOD in brain tissue after secondary brain injury with seawater immersion in rats. Turk Neurosurg. 2016;26(3):384-88.

29. Ogaly HA, Eltablawy NA, Abd-Elsalam RM. Antifibrogenic influence of Mentha piperita L. essential oil against CCl4-induced liver fibrosis in rats. Oxid Med Cell Longev. 2018;2018. 
30. Han C, Sun T, Xv G, Wang S, Gu J, Liu C. Berberine ameliorates CCl4-induced liver injury in rats through regulation of the Nrf2-Keap1-ARE and p53 signaling pathways. Mol Med Rep. 2019;20(4):3095-102.

31. Idoga ES, Ambali SF, Ayo JO, Mohammed A. Assessment of antioxidant and neuroprotective activities of methanol extract of Moringa oleifera Lam. leaves in subchronic chlorpyrifos-intoxicated rats. Comp Clin Path. 2018;27(4):917-25.

32. Lu L, Wu C, Lu B, et al. BabaoDan cures hepatic encephalopathy by decreasing ammonia levels and alleviating inflammation in rats. J Ethnopharmacol. 2020;249:112301.

33. Kong Y, Le Y. Toll-like receptors in inflammation of the central nervous system. Int Immunopharmacol. 2011;11(10):1407-14.

34. Mao S-S, Hua R, Zhao X-P, et al. Exogenous administration of PACAP alleviates traumatic brain injury in rats through a mechanism involving the TLR4/MyD88/NF-KB pathway. J Neurotrauma. 2012;29(10):1941-59.

35. Zhou Z, Hou J, Mo Y, et al. Geniposidic acid ameliorates spatial learning and memory deficits and alleviates neuroinflammation via inhibiting HMGB-1 and downregulating TLR4/2 signaling pathway in APP/PS1 mice. Eur J Pharmacol. 2020;869:172857.

36. Brown J, Wang H, Hajishengallis GN, Martin M. TLR-signaling networks: an integration of adaptor molecules, kinases, and cross-talk. J Dent Res. 2011;90(4):417-27.

37. Shim J-Y, Kim M-H, Kim H-D, Ahn J-Y, Yun Y-S, Song J-Y. Protective action of the immunomodulator ginsan against carbon tetrachloride-induced liver injury via control of oxidative stress and the inflammatory response. Toxicol Appl Pharmacol. 2010;242(3):318-25.

38. Vairappan B, Sundhar M, Srinivas BH. Resveratrol Restores Neuronal Tight Junction Proteins Through Correction of Ammonia and Inflammation in CCl 4-Induced Cirrhotic Mice. Mol Neurobiol. 2019;56(7):4718-29.

39. Yoshimura A, Shichita T. Post-ischemic inflammation in the brain. Front Immunol. 2012;3:132.

40. Kubera M, Obuchowicz E, Goehler L, Brzeszcz J, Maes M. In animal models, psychosocial stressinduced (neuro) inflammation, apoptosis and reduced neurogenesis are associated to the onset of depression. Prog Neuro-Psychopharmacology Biol Psychiatry. 2011;35(3):744-59.

41. Dowlati Y, Herrmann N, Swardfager W, et al. A meta-analysis of cytokines in major depression. Biol Psychiatry. 2010;67(5):446-57.

42. Millan MJ. The role of monoamines in the actions of established and "novel" antidepressant agents: a critical review. Eur J Pharmacol. 2004;500(1-3):371-84.

43. Damink SWMO, Jalan R, Redhead DN, Hayes PC, Deutz NEP, Soeters PB. Interorgan ammonia and amino acid metabolism in metabolically stable patients with cirrhosis and a TIPSS. Hepatology. 2002;36(5):1163-71.

44. Heidari R, Jamshidzadeh A, Niknahad H, et al. Effect of taurine on chronic and acute liver injury: Focus on blood and brain ammonia. Toxicol reports. 2016;3:870-79. 
45. Bosoi CR, Rose CF. Identifying the direct effects of ammonia on the brain. Metab Brain Dis. 2009;24(1):95-102.

46. Khan A, Shal B, Naveed M, et al. Matrine ameliorates anxiety and depression-like behaviour by targeting hyperammonemia-induced neuroinflammation and oxidative stress in CCl4 model of liver injury. Neurotoxicology. 2019;72:38-50.

47. Liu Y, Wen P, Zhang X, Dai Y, He Q. Breviscapine ameliorates CCl4-induced liver injury in mice through inhibiting inflammatory apoptotic response and ROS generation. Int J Mol Med. 2018;42(2):755-68.

48. Kurek A, Kucharczyk M, Detka J, et al. Pro-apoptotic action of corticosterone in hippocampal organotypic cultures. Neurotox Res. 2016;30(2):225-38.

49. Shaalan S, Radwan OK, Saleh H. Role of Wheat Germ Oil against Carbon Tetrachloride Induced Neurotoxicity in Brain Tissues of Adult Male Mice. Egypt J Zool. 2017;174(5542):1-18.

\section{Table}

Table 1: Sequence of primers used for RT-qPCR

\begin{tabular}{|c|c|c|}
\hline Genes & Forward primer $\left(5^{\prime}-3^{\prime}\right)$ & Reverse primer $\left(5^{\prime}-3^{\prime}\right)$ \\
\hline TLR2 & 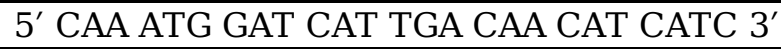 & 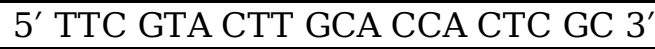 \\
\hline TLR4 & 5' GCTTGAATCCCTGCATAGAGGTAG 3' & 5' TCTTCAAGGGGTTGAAGCTCAG 3' \\
\hline MYD88 & 5' GGAACAGACCAACTATCGGC 3' & 5' GAGACAACCACTACCATCCG 3' \\
\hline $\mathrm{NF}-\square \mathrm{B}$ & 5' AAGGATGTCTCCACACCACTG 3' & 5' CACTGTCTGCCTCTCTCGTCT 3' \\
\hline Caspase3 & 5' CCTCAGAGAGACATTCATGG 3' & 5' GCAGTAGTCGCCTCTGAAGA 3' \\
\hline GAPDH & 5' CATCAACGGGAAGCCCATC 3' & 5' CTCGTGGTTCACACCCATC 3' \\
\hline
\end{tabular}

Table 2: MOLE pretreatment effect on the relative expression of TLR2, TLR4, MyD88, NF$\mathbf{K B}$, and caspase 3 as well as the protein levels of TNF- $\alpha$ and IL6 in the hippocampus (HC) and cerebral cortex (CC) of $\mathrm{CCl}_{4}$-injected mice. 


\begin{tabular}{|c|c|c|c|c|c|c|}
\hline & & & Control & $\mathrm{CCl}_{4}$ & MOLE & $\mathrm{CCl}_{4}+\mathrm{MOLE}$ \\
\hline \multirow{10}{*}{$\begin{array}{c}\text { Relative } \\
\text { mRNA } \\
\text { expression } \\
\text { (fold change } \\
\text { over control) }\end{array}$} & \multirow[t]{2}{*}{ TLR2 } & $\mathrm{HC}$ & $1.01 \pm 0.007071$ & $5.000 \pm 0.1414^{\mathrm{c}}$ & $1.090 \pm 007071^{\mathrm{y}}$ & $2.100 \pm 0.4950^{x}$ \\
\hline & & $\mathrm{CC}$ & $1.01 \pm 0.007071$ & $6.000 \pm 0.1414^{c}$ & $0.9800 \pm 007071^{y}$ & $2.800 \pm 0.4950^{y}$ \\
\hline & \multirow[t]{2}{*}{ TLR4 } & $\mathrm{HC}$ & $1.030 \pm 0.01414$ & $7.000 \pm 0.4243^{c}$ & $1.010 \pm 0.02121^{\mathrm{y}}$ & $3.500 \pm 0.3465^{y}$ \\
\hline & & CC & $1.010 \pm 0.01414$ & $7.000 \pm 0.4243^{c}$ & $1.020 \pm 0.02121^{\mathrm{y}}$ & $3.010 \pm 0.3465^{\mathrm{y}}$ \\
\hline & \multirow[t]{2}{*}{ MyD88 } & $\mathrm{HC}$ & $1.010 \pm 0.03512$ & $5.000 \pm 0.07071^{\mathrm{d}}$ & $1.020 \pm 0.01414^{\mathrm{z}}$ & $1.900 \pm 0.1131^{\mathrm{z}}$ \\
\hline & & CC & $1.000 \pm 0.02121$ & $5.000 \pm 0.07071^{d}$ & $1.000 \pm 0.01414^{\mathrm{z}}$ & $2.060 \pm 0.1131^{\mathrm{z}}$ \\
\hline & \multirow[t]{2}{*}{ NF-kB } & $\mathrm{HC}$ & $1.080 \pm 0.03512$ & $10.00 \pm 1.701^{b}$ & $1.010 \pm 007071^{\mathrm{x}}$ & $4.010 \pm 0.4050^{\mathrm{x}}$ \\
\hline & & $\mathrm{CC}$ & $1.010 \pm 0.03512$ & $6.000 \pm 1.701^{\mathrm{a}}$ & $1.050 \pm 007071^{\mathrm{w}}$ & $3.200 \pm 0.4050$ \\
\hline & \multirow{2}{*}{$\begin{array}{c}\text { Caspase } \\
3\end{array}$} & $\mathrm{HC}$ & $1.000 \pm 0.02121$ & $6.000 \pm 0.2121^{d}$ & $1.100 \pm 0.01414^{\mathrm{z}}$ & $2.900 \pm 0.1414^{\mathrm{z}}$ \\
\hline & & $\mathrm{CC}$ & $1.030 \pm 0.02121$ & $6.000 \pm 0.2121^{d}$ & $1.200 \pm 0.02121^{\mathrm{z}}$ & $2.700 \pm 0.1414^{\mathrm{z}}$ \\
\hline \multirow{4}{*}{$\begin{array}{l}\text { Protein level } \\
\quad(\mathrm{pg} / \mathrm{mg})\end{array}$} & \multirow[t]{2}{*}{ TNF- $\alpha$} & $\mathrm{HC}$ & $28.60 \pm 3.606$ & $118.0 \pm 6.010^{b}$ & $26.50 \pm 6.000 \times$ & $68.40 \pm 18.03^{w}$ \\
\hline & & $\mathrm{CC}$ & $33.70 \pm 3.606$ & $126.0 \pm 6.010^{b}$ & $35.10 \pm 6.000^{x}$ & $42.90 \pm 18.03^{\mathrm{x}}$ \\
\hline & \multirow[t]{2}{*}{ IL-6 } & $\mathrm{HC}$ & $52.10 \pm 8.910$ & $141.0 \pm 18.17^{b}$ & $36.10 \pm 1.000^{\mathrm{x}}$ & $82.30 \pm 12.59^{\mathrm{w}}$ \\
\hline & & CC & $39.50 \pm 8.910$ & $167.0 \pm 18.17^{b}$ & $38.40 \pm 1.000^{\mathrm{x}}$ & $64.50 \pm 12.59^{\mathrm{x}}$ \\
\hline
\end{tabular}

TLR: toll-like receptor, MYD88: myeloid differentiation primary response 88, NF-кB: nuclear factor kappa B, TNF- $\alpha$ : tumor necrosis factor- $\alpha$, IL-6: interleukin 6 . All data are represented as mean $\pm \mathrm{SD}, \mathrm{n}=8 .{ }^{\mathrm{a}}$ indicates $\mathrm{P}<0.05,{ }^{\mathrm{b}}$ indicates $\mathrm{P}<0.01,{ }^{\mathrm{c}}$ indicates $\mathrm{P}<$ 0.001, and ${ }^{\mathrm{d}}$ indicates $\mathrm{P}<0.0001$ compared to control group. ${ }^{\mathrm{w}}$ indicates $\mathrm{P}<0.05$, $\mathrm{x}$ indicates $\mathrm{P}<0.01, \mathrm{y}$ indicates $\mathrm{P}<0.001$, and ${ }^{\mathrm{z}}$ indicates $\mathrm{P}<0.0001$ compared to $\mathrm{CCl}_{4}$ group.

\section{Figures}


Fig. 1
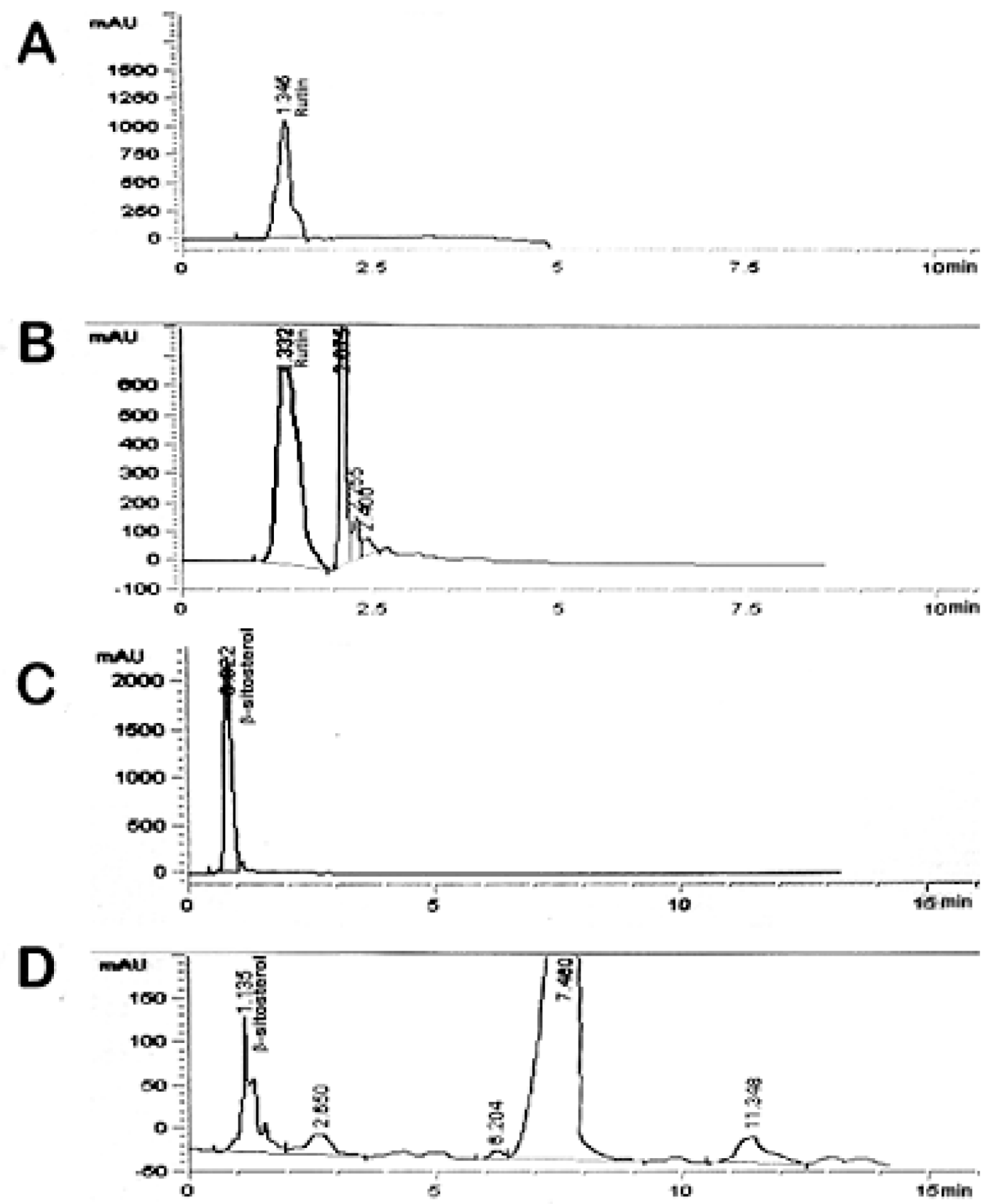

HPLC chromatograms ( $\lambda 254 \mathrm{~nm}$ ) of (A) rutin reference standard (retention time 1.3 min) and (B) ethanolic extract of MOL leaves; HPLC chromatograms $(\lambda 210 \mathrm{~nm})$ of (C) $\beta$-sitosterol reference standard (retention time $0.8 \mathrm{~min}$ ) and (D) ethanolic extract of MOL leaves.

\section{Figure 1}

High-performance liquid chromatography (HPLC) analysis of MOLE. 
Fig. 2

ALT

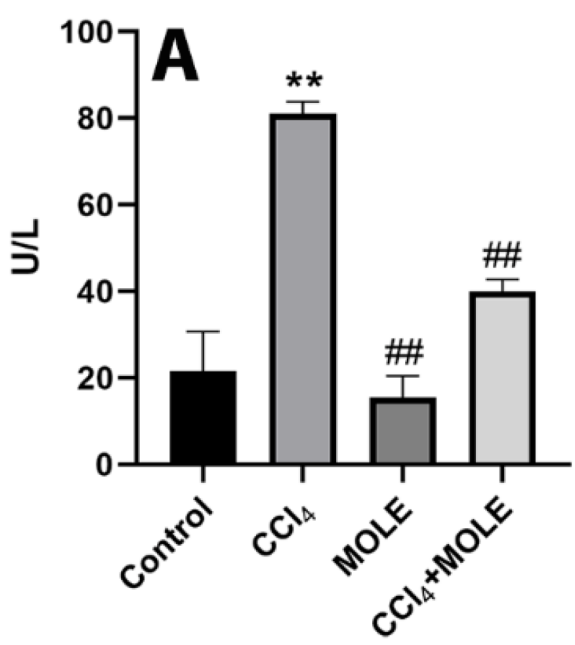

Ammonia

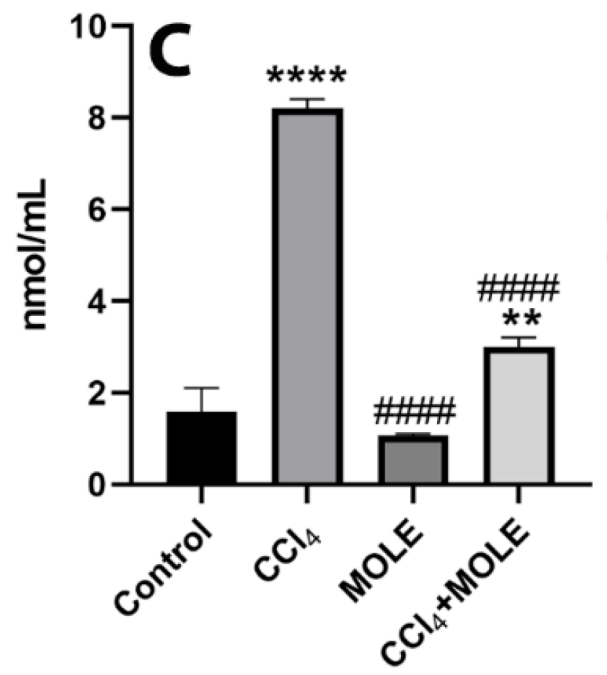

AST

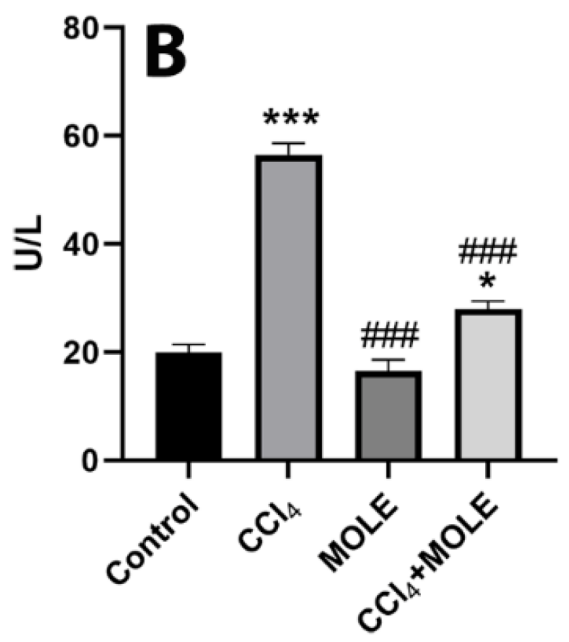

Cortecosterone

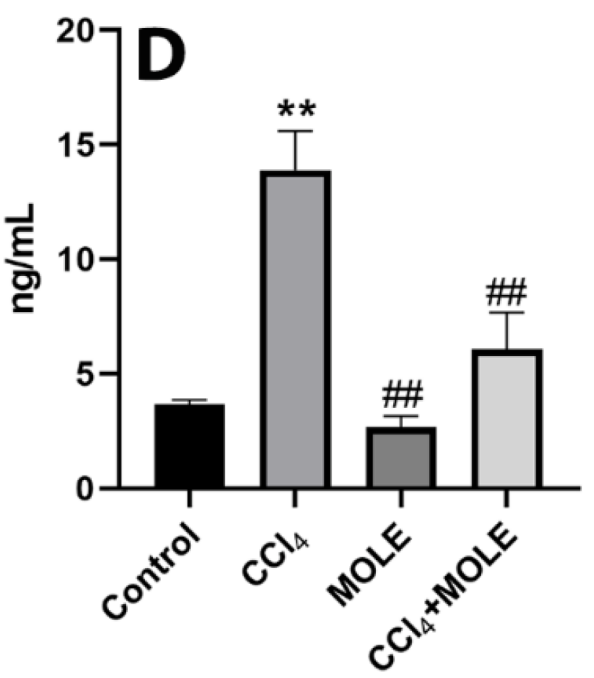

MOLE pretreatment protects against the increase in the levels of alanine aminotransferase (ALT) (A), aspartate aminotransferase (AST) (B), ammonia (C), and corticosterone (D) induced by $\mathrm{CCl}_{4}$. All data are represented as mean $\pm \mathrm{SD}, \mathrm{n}=8 . * \mathrm{P}<0.05, * * \mathrm{P}<0.01, * * * \mathrm{P}<0.001$ and $* * * * \mathrm{P}<0.0001$ compared to control group. \#\#P $<0.01$, \#\#\#P $<0.001$, and $\# \# \#$ $\quad<0.0001$ compared to $\mathrm{CCl}_{4}$ group.

\section{Figure 2}

Protective effect of MOLE pretreatment on serum aminotransferases, ammonia, and corticosterone levels. 
Fig. 3
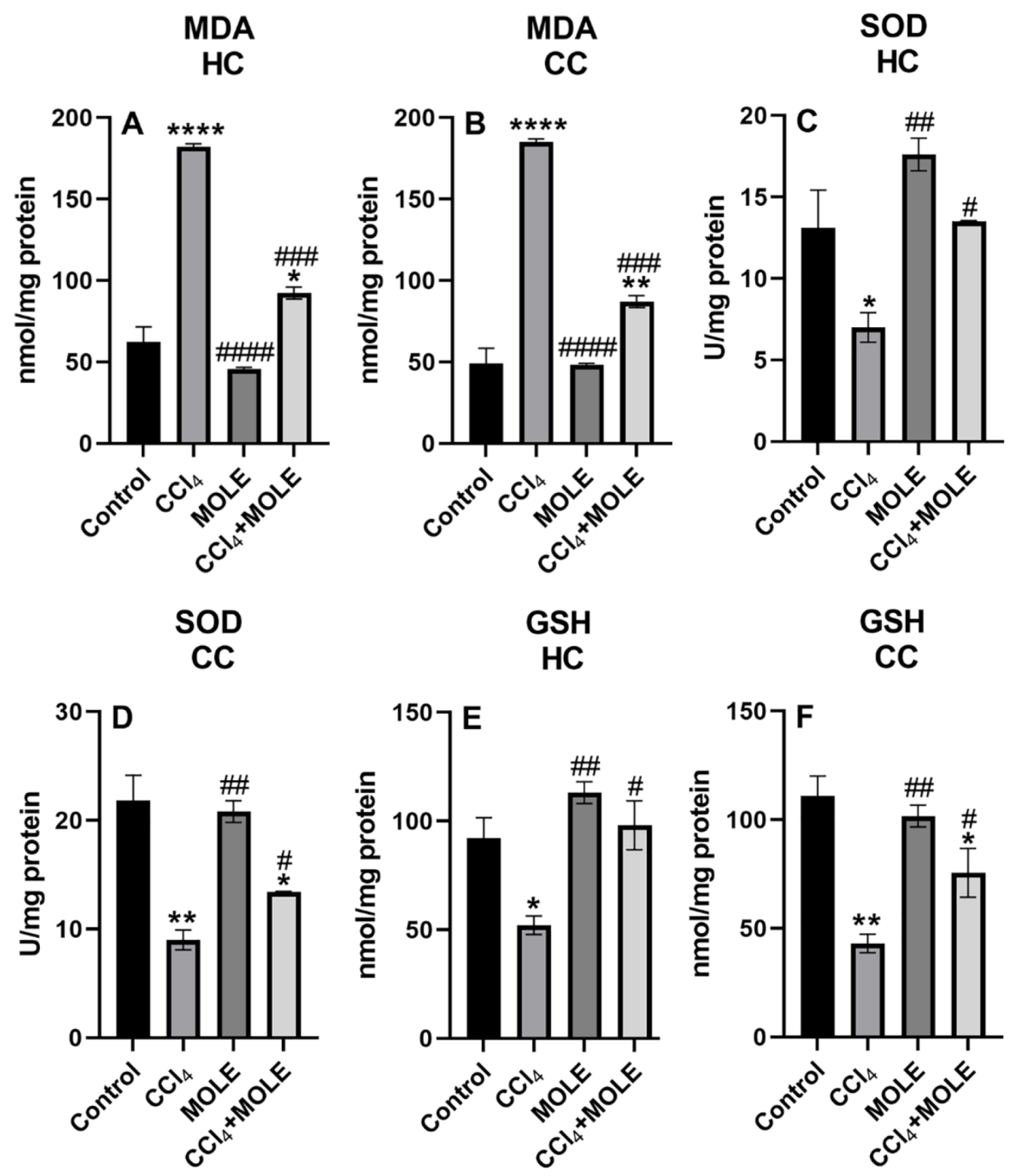

MOLE pretreatment attenuates elevated LPO, represented by malondialdehyde (MDA), by $\mathrm{CCl}_{4}$ toxicity in the $\mathrm{HC}(\mathrm{A})$ and $\mathrm{CC}(\mathrm{B})$. It also restores antioxidant mechanisms, represented by superoxide dismutase (SOD) $(\mathrm{C}, \mathrm{D})$ and reduced glutathione (GSH) (E, F) affected by $\mathrm{CCl}_{4}$ toxicity. All data are represented as mean $\pm \mathrm{SD}, \mathrm{n}=8 . * \mathrm{P}<0.05, * * \mathrm{P}<0.01$, and $* * * * \mathrm{P}<0.0001$ compared to control group. $\# \mathrm{P}<0.05$, \#\#P $<0.01$, \#\#\#P $<0.001$, and \#\#\#\#P $<0.0001$ compared to $\mathrm{CCl}_{4}$ group.

\section{Figure 3}

MOLE pretreatment impacts lipid peroxidation (LPO) and antioxidant mechanisms in the hippocampus (HC) and cerebral cortex (CC). 
Fig. 4

FST

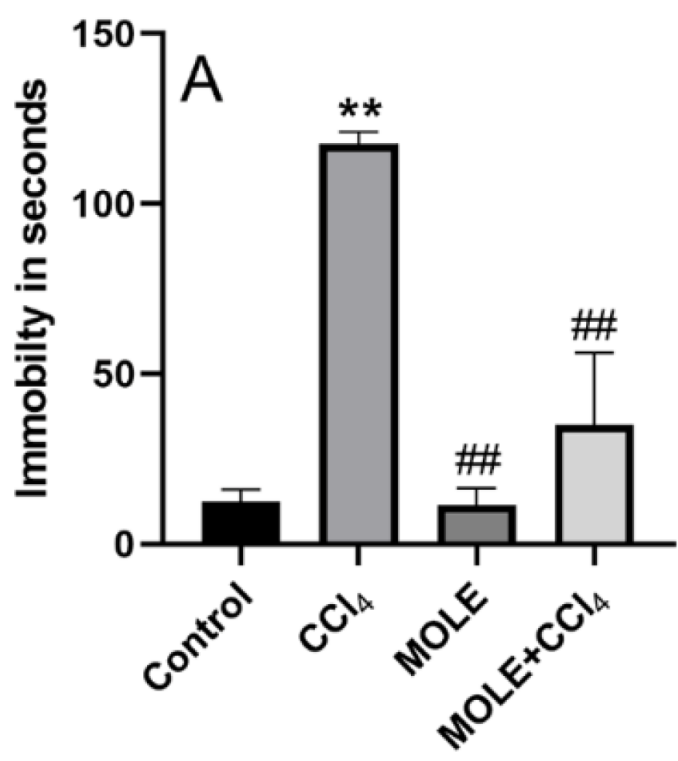

\section{TST}

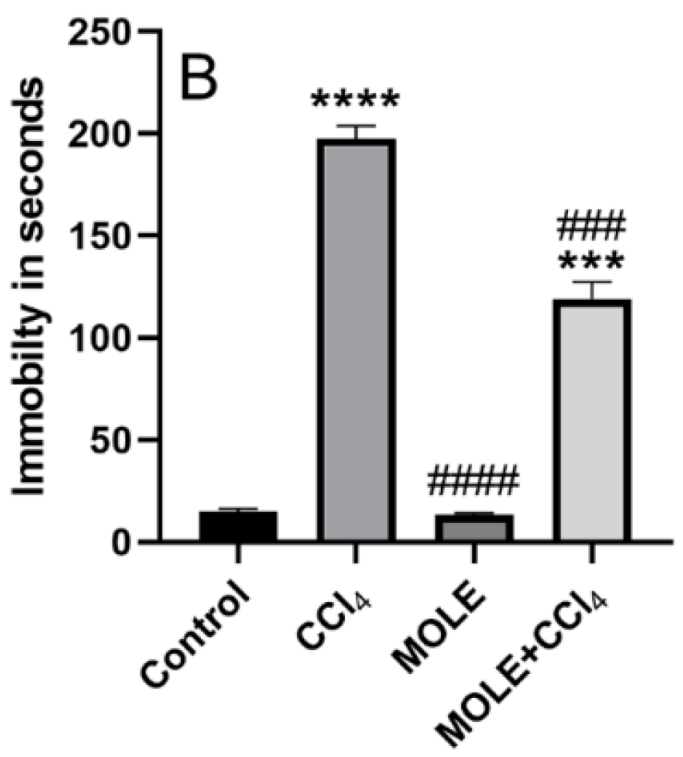

MOLE pretreatment protects against the exhibition of depression-like behaviors induced by $\mathrm{CCl}_{4}$ based on forced swimming test (FST) (A) and tail suspension test (TST) (B). All data are represented as mean $\pm \mathrm{SD}, \mathrm{n}=8$. $* * \mathrm{P}<$ $0.01, * * * \mathrm{P}<0.001$, and $* * * * \mathrm{P}<0.0001$ compared to control group. \#\#P $<0.01$, \#\#\#P<0.001, and \#\#\#\#< 0.0001 compared to $\mathrm{CCl}_{4}$ group.

Figure 4

MOLE pretreatment influence on the depression-like behaviors induced by $\mathrm{CCl} 4$. 
Fig. 5
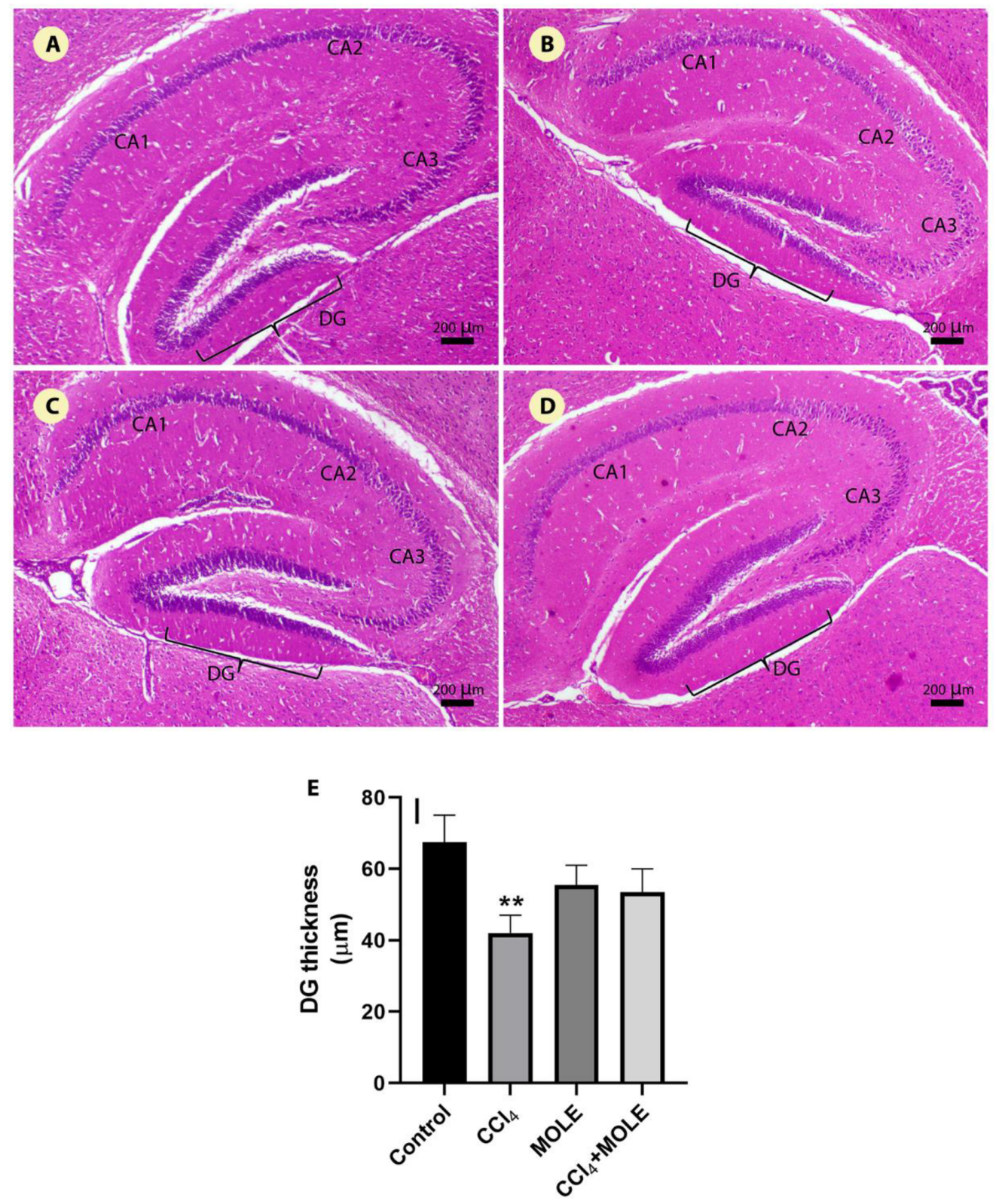

Micrographs (A, B, C, and D) show coronal sections in the HC stained with H\&E (40x magnification, scale bar $=200 \mu \mathrm{m}$ ) of control, $\mathrm{CCl}_{4}, \mathrm{MOLE}$, and $\mathrm{CCl}_{4}+\mathrm{MOLE}$ groups, respectively. CA1, CA2, and CA3 denote different regions of cornu ammonis (CA). DG denotes dentate gyrus. Micrograph (E) shows that MOLE pretreatment protects against the reduction in $\mathrm{DG}$ thickness induced by $\mathrm{CCl}_{4}$. All data are represented as mean $\pm \mathrm{SD}, \mathrm{n}=8$. $* * \mathrm{P}<0.01$ compared to control group.

\section{Figure 5}

MOLE pretreatment effect on the induced histopathological changes in the hippocampus $(\mathrm{HC})$ by $\mathrm{CCl} 4$ administration. 
Fig. 6
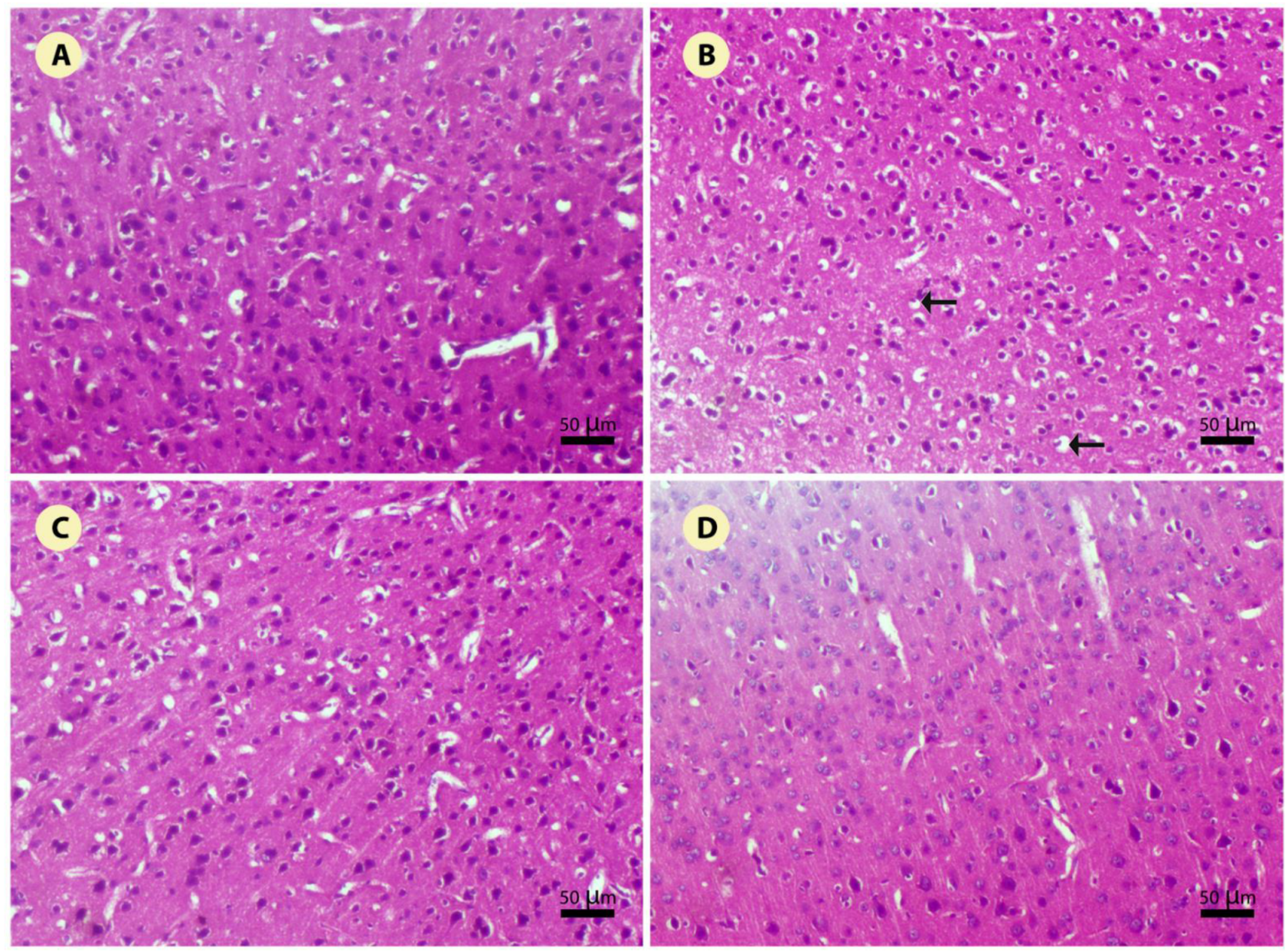

Micrographs (A, B , C, and D) show coronal sections in the CC (100x magnification, scale bar $=50 \mu \mathrm{m})$ of control, $\mathrm{CCl}_{4}, \mathrm{MOLE}$, and $\mathrm{CCl}_{4}+\mathrm{MOLE}$ groups, respectively. Neuron degeneration $(\mathrm{Nd})$ is manifested in the $\mathrm{CCl}_{4}$ group but MOLE pretreatment protected the neurons against this effect.

\section{Figure 6}

MOLE pretreatment effect on the induced histopathological changes in the cerebral cortex (CC) by $\mathrm{CCl} 4$ administration.

\section{Supplementary Files}

This is a list of supplementary files associated with this preprint. Click to download.

- Highlights.docx

- NC3RsARRIVEchecklist.pdf 